\title{
Lessons from a Key Parameter of Coaxial Electrospinning for Engineering Education to College Students
}

\author{
Zhe-Peng Liu ${ }^{1, *}$ \\ School of Medical Instrument and Food Engineering \\ University of Shanghai for Science and Technology \\ 516 Jungong Road, Shanghai 200093, China \\ zhepengliu@126.com
}

\author{
Zhangbin Feng2, Guomei Zhao2, Changsheng He2, \\ Dengguang $\mathrm{Yu} 2$, \\ School of Materials Science and Engineering \\ University of Shanghai for Science and Technology \\ 516 Jungong Road, Shanghai 200093, China \\ ydg017@usst.edu.cn
}

\begin{abstract}
In the universities of science and technology, engineering education is one of the most important part to train college students' innovation ability and their capability of solving complex engineering problems. In this paper, a new procedure is exhibited for carrying out effective engineering education with modified coaxial electrospinning as an advanced nanotechnology and one of its key parameters (sheath-to-core fluid flow rate ratio) as a model. The link between this key parameter and a series of disciplines can provide a unique perspective for engineering education, and it can act as a starting point of a new procedure to develop students' comprehensive ability in innovating or resolving complex engineering problems. Based on present approach as a leading example, many other similar procedures can be designed and refined from a variety of advanced technologies to conduct vivid and effective engineering educations.
\end{abstract}

Keywords-Key Parameter; Coaxial Electrospinning; Engineering Education; College Students; Flow rate

\section{BACKGROUND}

"Engineering" is derived from the Latin ingenium, meaning "cleverness" and ingeniare, meaning "to contrive, devise". It is the creative application of science, technology, mathematical methods, and empirical evidence to the design, innovation, construction, and maintenance of materials, structure, machines, devices, systems, processes, and organizations [1]. The discipline of engineering encompasses a broad range of more specialized field of engineering. As an important branch, material science and engineering often emphasize on the application of advanced technology in creating new kinds of functional materials. Particularly for the students majoring in this field and aiming to become excellent engineers, the grasp of several advanced technologies and their related scientific fundamental theories is pre-requisite.

Engineering education is the activity of imparting knowledge and principles to the professional practice of engineering. It includes the initial education (Bachelor and or Mater degree) for journey of becoming an engineer, and any advanced education and specializations that follow. One important content of engineering education is to teach the college students about the creative application of scientific principles to design or develop structures, machines, apparatus, or manufacturing processes, or to forecast their behavior under specific operating conditions, or works utilizing them singly or in combination; or to construct or operate the same with full cognizance of their design. And another important content is to solve engineering problems. Usually, multiple reasonable solutions exist, so engineers must evaluate the different design choices on their merits and choose the solution that best meets their requirements. No matter new engineering design or new solutions for engineering problems, the key element is to focus on the key points. It is suggested that compromises are at the heart of "low-level" engineering designs, while at a higher level the best design is one which eliminates the core contradiction causing the problem.

Advanced technologies can be excellent materials for serving as the foundation for engineering education at the university level, particularly for those belong to the universities of science and technology. Many contents can be refined from the applications of advanced technologies for an improved and "Keep pace with the times" engineering education to the college students.

In this paper, several advanced nanotechnologies (electrospinning, coaxial electrospinning and modified coaxial electrospinning) are explored as materials for engineering eduction to the college students majoring in materials science and engineering field [2-5]. Particularly in the modified coaxial electrospinning processes, the influence of a key parameter, i.e. sheath-to-core fluid flow rate ratio on the modified coaxial electrospinning and its products will be discussed in detail. The linkages of this key parameter with a series of disciplines can provide a unique angle for engineering education, and it can act as a starting point of a new procedure for fostering the comprehensive ability of students in innovation or resolving the complex engineering problems. 


\section{ELECTROSPINNING AND ITS ENGINEERING MEANINGS}

Electrospinning is formerly termed as electrostatic spinning a peer of the traditional wet spinning, dry spinning and melt spinning [6-7]. From its definition, it is very clear that "electrostatic energy" is exploited to "spin" working fluids into fibers [8]. Thus, it has often the similar fundamental problems with electrospraying, in which "electrostatic energy" is exploited to "spray" working fluids into particles [9-14].

During the past two decades, electrospinning is fastly developing to the double-fluid coaxial and side-by-side electrospinning, to multiple-fluid tri-axial electrospinning and other types of complex electrospinning processes. In these processes, several working fluids are treated using electrostatic energy simultaneously to create solid nanoproducts with the designed complicated inner structures [15-21].

Apparently, these advanced nanotechnologies are fine teaching materials for the undergraduate and postgraduate students. These teaching materials can be refined from the new material designs, the operation of electrospinning processes, and a series of engineering problems needed to be solved in situ. Among these advanced nanotechnologies, modified coaxial electrospinning is the best one to act as an example to impart the students about both the operation and also the microformation mechanism of nanofibers under the optimized working conditions.

Shown in Fig. 1 are diagrams of the single-fluid blending electrospinning and the two-fluid coaxial electrospinning processes. The modified coaxial electrospinning is derived from the traditional coaxial electrospinning processes through that un-spinnable solutions are exploited as the sheath working fluids to carry out the electrospinning processes. Different with the traditional coaxial electrospinning, the modified coaxial processes can generate nanofibers with a wide variety of inner structural properties, such as monolithic, double-layer, core-sheath, ultra-thin nanocoating, and also surface modification with functional small molecules [22-26].
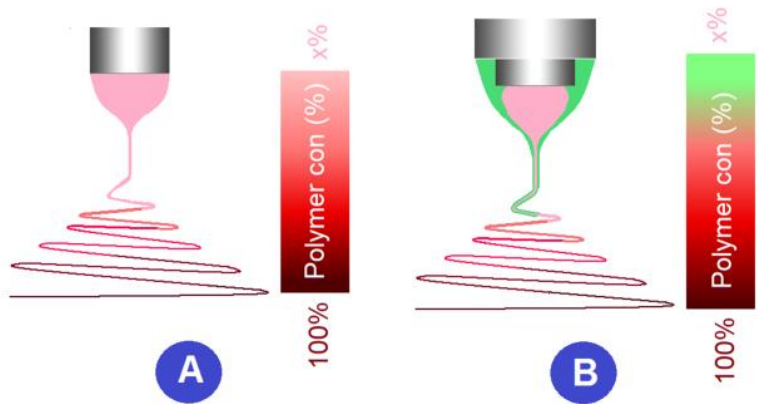

Fig. 1 Diagrams about blending electrospinning (A) and coaxial electrospinning (B).

\section{A SERIES OF PARAMETERS WITH DIFFERENT ROLES DURING BOTH BLENDING ELECTROSPINNING AND COAXIAL ELECTROSPINNING}

"Shown in Fig. 2, the parameters during the blending electrospinning and coaxial electrospinning processes can be similarly divided into three categories, properties of the working fluids, operational parameters, and environmental conditions. The further subdivision of these parameters include solvent, concentration of filament-forming polymer, and additive of the working fluid; applied high voltage, flow rate of the working fluid, and needle-to-collector distance for nanofiber deposition of the operational conditions; and temperature and apparent humidity of the working environment.

Needless to say, all these parameters should have a profound influence on the electrospinning process and also the quality of resultant nanofibers. However, based on the microformaion mechanisms of nanofibers, these parameters should exert their influence at a different extent. Because the key step is the interaction between the working fluids and the electrostatic energy, thus, flow rate of the working fluid is the most important parameter in a blending electrospinning process. However, when the modified coaxial electrospinning is implemented, there are two separate flow rates, one is the sheath fluid and the other is the core solution. In this case, a key parameter taking both of them into consideration, i.e. the sheath-to-core fluid flow rate ratio stands out from others parameters to project its important role in both controlling the working process and also manipulating the quality of final nanofibers.

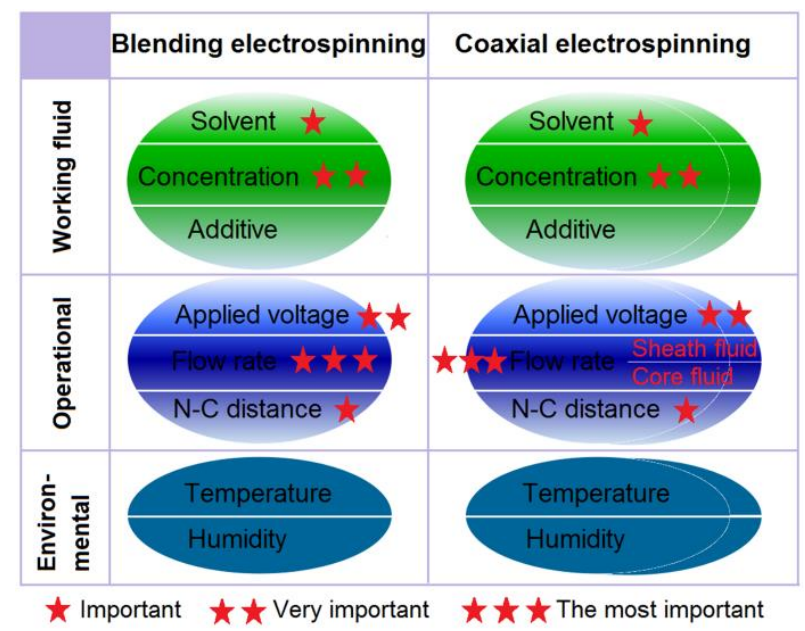

Fig. 2 The importance of a series of parameters during both blending electrospinning and coaxial electrospinning.

\section{THE INFLUENCE OF KEY PARAMETER SHEATH-TO-CORE FLUID FLOW RATE RATIO ON THE MODIFIED COAXIAL ELECTROSPINNING AND ITS PRODUCTS}

From a standpoint of the final products--electrospun solid nanofibers, the applied high voltage is also a very important parameter [27-29]. However, when the modified coaxial electrospinning is carried out, the sheath-to-core fluid flow rate ratio should play a vital role on the variations of spinning processes and also the morphology of resultant nanofibers. 
Shown in Fig. 3, when a suitable sheath-to-core fluid flow rate ratio $(\mathrm{R}=\mathrm{Fs} / \mathrm{Fc}$, where $\mathrm{Fs}$ and $\mathrm{Fc}$ represent the absolute flow rates of the sheath and core fluids, respectively), a reasonable compound Taylor cone will be formed, and the resultant nanofibers should have a linear morphology without any beads or spindles on them. However, when an inappropriate larger $\mathrm{R}$ is provided, although the compound Taylor core is still in right organization, the resultant nanoproducts would be a beads-on-a-string or a spindles-on-astring morphology, suggesting no high quality linear nanofibers can be achieved. When an excessive sheath fluid flow rate is provided, i.e. an extremely larger R, it is impossible to hold a stable compound Taylor cone, the sheath fluid and the core fluid will depart from each other. Meanwhile, the final resultant products should be a hybrid mixture of electrospun nanofibers and electrosprayed microparticles. Besides, a suitable $\mathrm{R}$ value is also a key role in generating nanofibers at a larger scale.



Fig. 3 The influence of key parameter sheath-to-core fluid flow rate ratio on the working processes of modified coaxial electrospinning and its final products.

\section{THE LINKAGES OF THE KEY PARAMETERS OF COAXIAL ELECTROSPINNING WITH A SERIES OF DISCIPLINES CAN \\ PROVIDE A UNIQUE ANGLE FOR ENGINEERING EDUCATION}

In the engineering education, two very important branches are the innovation education and the ability of resolving complex engineering problems. Both of them need the students have an interdisciplinary background knowledge. In the modified coaxial electrospinning processes, their key parameter, i.e. sheath-to-core fluid flow rate ratio would have a close linkage with a series of disciplines, which can provide a supporting platform for deepening engineering education.

Shown in Fig. 4, the suitable selection of $\mathrm{R}$ value for a smooth and robust working process would take the following parameters into consideration, the pumped speed of pumper, the properties of working polymer solutions, and the conductivities of the sheath and core fluids. Thus, it is inevitable that disciplines such as fluid mechanics, rheology, electrodynamics would be involved. On the other hand, the resultant nanofibers would be evaluated through a series of analysis methods, and thus would call for the knowledge about nanoscience, analytical science and applied sciences such as environment, energy, health and hygiene.

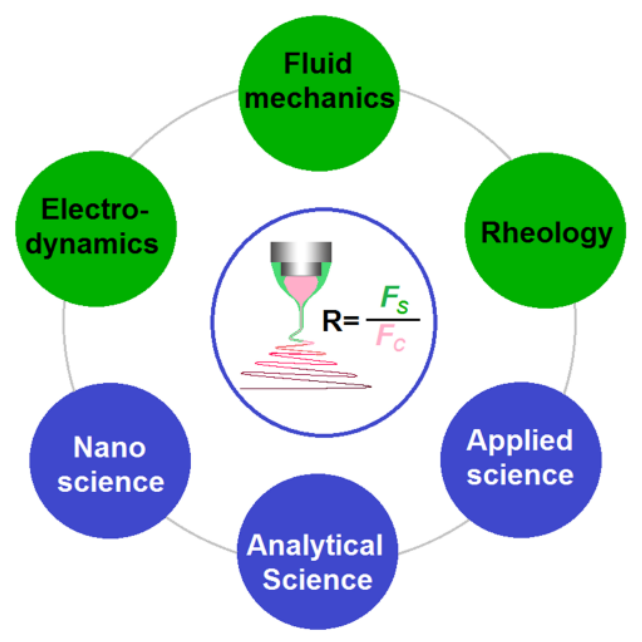

Fig. 4 The deep linkages of the key parameter of coaxial electrospinning with a series of disciplines, which provide a special angle for engineering education.

\section{THE KEY PARAMETER OF COAXIAL ELECTROSPINNING CAN ACT AS A STARTING POINT OF A NEW PROCEDURE FOR FOSTERING THE COMPREHENSIVE ABILITY OF STUDENTS}

Base on the above-mentioned knowledge, it is clear that the key parameter of coaxial electrospinning, sheathto-core fluid flow rate tario, can act as a starting point for developing a new teaching procedure, which should be very useful for fostering the comprehensive ability of college students, particularly those majoring in materials science and engineering.

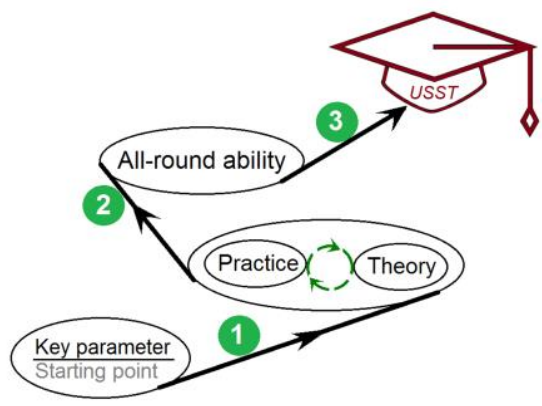

Fig. 5 With the key parameter of coaxial electrospinning as a starting point, a new procedure can be built for fostering the all-round ability of the college students.

Shown in Fig. 5, with the key parameter as a starting point, a series of its variations would result in a series of practical experiments and meanwhile a series of theories from different disciplines would be involved. With these circles of training between the practices and theories, the students can be trained to improve not only the theroetical knowledge, the practical experiences about advanced nanotechnologies, but also their capability of linking practice and theory. Standing on this 
training platform, the innovation engineering ability and the capability of resolving complex engineering problems should be improved substantially. Thus, this procedure can pave a way for cultivating the college students, providing an easy way for them to become the excellent engineers, a goal of many universities of science and technology. Along this procedure, many other similar procedures can be designed and refined from all kinds of advanced technologies for engineering educations.

\section{SUMMARY}

In summary, based on an advanced "top-down" nanotechology, i.e. modified coaxial electrospinning as an example, a series of teaching materials can be refined from it. Particularly, a new procedure is investigated for implementing effective engineering education with one of the key parameters (sheath-to-core fluid flow rate ratio) as a vital variation. The linkages of sheath-to-core fluid flow rate ratio with a series of interrelate disciplines can provide a useful platform for engineering education. It can act as a useful starting point of a new training procedure for fostering the all-round ability of students in innovation or resolving the complex engineering problems.

\section{ACKNOWLEDGMENT}

The financial supports from the following projects are appreciated: the Shanghai Education Science Research Project (C17058), the National Natural Science Foundation of China (No. 51373101), the 2017 Graduate curriculum reform project in USST, and the College Student Innovation Project of USST (Nos. SH2018).

\section{REFERENCES}

[1] D. Blockley, "Engineering: a very short introduction," New York: Oxford University Press. ISBN 978-0-19-957869-6, 2012

[2] X. Liu, W. Shao, M. Luo, J. Bian, D.G. Yu, "Electrospun blank nanocoating for improved sustained release profiles from medicated gliadin nanofibers," Nanomaterials, vol.8, Article ID 184 (11 pages), 2018.

[3] Y.H. WU, H.P. Li, X.X. Shi, J. Wan, Y.F. Liu, and D.G. Yu, "Effective utilization of the electrostatic repulsion for improved alignment of electrospun nanofibers," J. Nanomater., vol.2016, Article ID2067383, 2016.

[4] G.Z. Yang, H.P. Li, J.H. Yang, J. Wan, and D.G. Yu, "Influence of working temperature on the formation of electrospun polymer nanofibers," Nanoscale Res. Lett., vol.12, Article 15, January 2017.

[5] Y.Y. Yang, Z.P. Liu, D.G. Yu, K. Wang, P. Liu, X. Chen, "Colonspecific pulsatile drug release provided by electrospun shellac nanocoating on hydrophilic amorphous composites," Int. J. Nanomed., vol.2018, DOI: 10.2147/IJN.S154849, 2018.

[6] Q. Wang, D.G. Yu, L.L. Zhang, X.K. Liu, Y.C. Deng, and M. Zhao, "Electrospun hypromellose-based hydrophilic composites for rapid dissolution of poorly water-soluble drug," Carbohydr. Polym., vol.174, pp.617-625, Oct, 2017

[7] X.Y. Li, Z.B. Zheng, D.G. Yu, X.K. Liu, Y.L. Qu, and H.L. Li, "Electrosprayed sperical ethylcellulose nanoparticles for an improved sustained-release profile of anticancer drug," Cellulose, vol.24, pp.5551-5564, 2017.

[8] D.G. Yu, C. Yang, M. Jin, G.R. Williams, H. Zou, X. Wang, et al, "Medicated Janus fibers fabricated using a Teflon-coated side-by-side spinneret," Colloid. Surface B, vol.138, pp.110-116, Feburary 2016.

[9] K. Wang, X.K. Liu, X.H. Chen, D.G. Yu, Y.Y. Yang, and P. Liu, "Electrospun hydrophilic Janus nanocomposites for the rapid onset of therapeutic action of helicid," ACS Appl. Mater. Interfaces, vol.10, pp.2859-2867, 2018

[10] Y.H. Wu, D.G. Yu, J.J. Li, Q. Wang, H.P. Li, and X.Y. Li, "Medicated multiple-component polymeric nanocomposites fabricated using electrospraying," Polym. Polym. Compos., vol.25, pp.57-62, 2017.

[11] Z.P. Liu, Y.Y. Zhang, D.G. Yu, D. Wu, and H.L. Li, "Fabrication of sustained-release zein nanoparticles via modified coaxial electrospraying,” Chem. Eng. J., vol.334, pp.807-816, 2018.

[12] Y.Y. Yang, M. Zhang, Z.P. Liu, K. Wang, and D.G. Yu, "Meletin sustained-release gliadin nanoparticles prepared via solvent surface modification on blending electrospraying," App. Surf. Sci., vol.434, pp.1040-1047, 2018.

[13] K. Wang, H.F. Wen, D.G. Yu, Y. Yang, and D.F. Zhang, "Electrosprayed hydrophilic nanocomposites coated with shellac for colon-specific delayed drug delivery," Mater. Design, vol.143, pp.248255, 2018

[14] Z.P. Liu, L.L. Zhang, Y.Y. Yang, D. Wu,G. Jiang, and D.G. Yu, "Preparing composite nanoparticles for immediate drug release by modifying electrohydrodynamic interfaces during electrospraying,' Powd. Technol., vol.327, pp.179-187, 2018.

[15] D.G. Yu, H.P. Li, C. Yang, J.J. Li, Q. Wang, and G.R. Williams, "Double-pulsatile release core-shell fibers fabricated using modified tri-axial electrospinning," J. Control. Release, vol.259, pp.e24-e25, 2017.

[16] C. Yang, D.G. Yu, D. Pan, X.K. Liu, X. Wang, S.W.A. Bligh, et al, "Electrospun pH-sensitive core-shell polymer nanocomposites fabricated using a tri-axial processes," Acta Biomater., vol.35, pp.77-86, April 2016.

[17] D.G. Yu, J.J. Li, M. Zhang, and G.R. Williams, "High-quality Janus nanofibers prepared using three-fluid electrospinning," Chem. Commun., vol.53, pp.4542-4545, April 2017.

[18] G.Z. Yang, J.J. Li, D.G. Yu, M.F. He, J.H. Yang, and G.R. Williams, "Nanosized sustained-release drug depots fabricated using modified triaxial electrospinning," Acta Biomater., vol.53, pp.233-241, April 2017.

[19] Y. Xu, J.J. Li, D.G. Yu, G.R. Williams, J.H. Yang, and X. Wang, "Influence of the drug distribution in electrospun gliadin fibers on drugrelease behavior," Eur. J. Pharm. Sci., vol.106, pp.422-430, August 2017.

[20] Y.H. WU, C. Yang, X.Y. Li, J.Y. Zhu, and D.G. Yu, "Medicated nanofibers fabricated using $\mathrm{NaCl}$ solutions as shell fluids in a modified coaxial electrospinning," J. Nanomater., vol.2016, Article ID 8970213. 2016.

[21] Q. Wang, D.G. Yu, S.Y. Zhou, C. Li, and M. Zhao, "Fabrication of amorphous electrospun medicated-nanocomposites using a Teflonbased concentric spinneret," e-Polymer, vol.18, pp.3-11, 2018.

[22] Y.H. Wu, D.G. Yu, H.P. Li, X.Y. Wu, and X.Y. Li, "Medicated structural PVP/PEG composites fabricated using coaxial electrospinning," e-Polymers, vol.17, pp.39-44, January 2017.

[23] Q. Wang, H.P. Li, C. Yang, J.J. Li, and D.G. Yu, "Beads-on-a-string amorphous solid dispersion fabricated using a modified coaxial electrospinning," J. Control. Release, vol.259, pp.e111-e112, 2017.

[24] J.J. Li, Chen Yang, Hai-Peng Li, Qing Wang, and Deng-Guang Yu, "Oral controlled release in accordance with drug adsorption biological rhythm provided by an electrospun structural amorphous solid dispersion," J. Control. Release, vol.259, pp.e61-e62, 2017.

[25] M. Jin, D.G. Yu, C.F.G.C. Geraldes, G.R. Williams, and S.W.A. Bligh, "Theranostic fibers for simultaneous imaging and drug delivery," Mol. Pharm., vol.13, pp.2457-2465, July 2016.

[26] H.F. Wen, C. Yang, D.G. Yu, X.Y. Li, and D.F. Zhang, "Electrospun zein nanoribbons for treatment of lead-contained wastewater," Chem. Eng. J., vol.290, pp.263-272, April 2016.

[27] M. Jin, D.G. Yu, X. Wang, C.F.G.C. Geraldes, G.R. Williams, and S.W.A. Bligh, "Electrospun contrast agent-loaded fibers for colontargeted MRI," Adv. Healthcare Mater., vol.5, pp.977-985, April 2016.

[28] B. Sanchez-Vazquez, A.J. Amaral, D.G. Yu, G. Pasparakis, and G.R. Williams, "Electrosprayed Janus particles for combined photochemotherapy,” AAPS PharmSciTech, vol.8, pp.1460-1468, 2017.

[29] Z. Zhang, W. Li, G. Wang, Y.L. Qu, and D.G. Yu, "Electrospun 4th generation solid dispersions of poorly water-soluble drug utilizing two different processes," J. Nanomater. Vol.2018, Article ID 2012140, 2018. 